\title{
Pulmonary interstitial emphysema
}

\author{
A GREENOUGH, A K DIXON, AND N R C ROBERTON
}

University Departments of Paediatrics and Radiology, New Addenbrooke's Hospital, Cambridge

SUMMARY Forty one of 210 preterm infants ventilated for respiratory distress syndrome in a three year period had radiological evidence of pulmonary interstitial emphysema. The development of this condition was significantly associated with malpositioning of the endotracheal tube in a main bronchus and the use of high peak pressure ventilation. Pulmonary interstitial emphysema was associated with a significant increase in the number of pneumothoraces, intraventricular haemorrhages, and the need for prolonged respiratory support, but did not increase mortality. Although in 12 infants in whom fast rate ventilation was used there was a significant reduction in the number of pneumothoraces, outcome was not altered in any other way. Fast rate ventilation may be of greater benefit if initiated before the development of pulmonary interstitial emphysema.

Preterm infants ventilated for respiratory distress syndrome are particularly prone to the development of pulmonary interstitial emphysema. ${ }^{1}$ This condition is associated with an increased morbidity as it poses two major problems for the infant. Firstly, the presence of widespread blebs of interstitial air further aggravates the already severe ventilation perfusion imbalance in the lungs of infants with respiratory distress syndrome, creating an even larger intrapulmonary shunt which, in some cases, results in severe and fatal hypoxaemia. ${ }^{1}$ Secondly, pulmonary interstitial emphysema commonly progresses to a pneumothorax ${ }^{2}$ which approximately doubles the mortality in infants with respiratory distress syndrome ${ }^{3}$ and is often associated with the development of an intraventricular haemorrhage. ${ }^{4}$

Recently, success in the management of severe pulmonary interstitial emphysema has been reported in a small number of babies, using either high frequency (480 to $720 /$ minute) $)^{5}$ or fast rate (120 to 140 /minute), low pressure (less than $15 \mathrm{~cm} \mathrm{H}_{2} \mathrm{O}$ ) ventilation. ${ }^{6}$

We have studied the incidence, aetiological associations, and morbidity of pulmonary interstitial emphysema in preterm babies in the Neonatal Intensive Care Unit in Cambridge ventilated for respiratory distress syndrome during the years 1980-83, and have assessed the effect of fast rate ventilation on the morbidity and mortality of this condition.

\section{Patients and methods}

We reviewed retrospectively the notes and chest radiograph reports of 254 babies ventilated on the unit during the three year period August 1980 to July 1983. Eight infants with fatal congenital abnormalities (Potter's syndrome and chromosomal abnormalities) were immediately excluded from the study. A total of 210 babies of gestational age 24 to 35 weeks were ventilated because of increasing respiratory failure due to the respiratory distress syndrome. Respiratory distress syndrome was diagnosed on the basis of classic clinical features: cyanosis in air, retractions and an expiratory grunt developing in the first hours of life and persisting for at least 48 hours, and a chest radiograph showing an air bronchogram and diffuse atelectasis. Intraventricular haemorrhage was diagnosed by real time ultrasound scan; only haemorrhages greater in size than a subependymal bleed are reported in the present study.

The original chest radiograph reports had been issued by a radiologist who had only limited knowledge of the infant's clinical condition (essentially 'blind'). Those radiographs showing pulmonary interstitial emphysema, as described by Campbell, ${ }^{7}$ were subsequently reviewed. The timing of the development of the condition was noted and a careful assessment of endotracheal tube siting was made. The first chest radiograph to show evidence and that showing the worst pulmonary interstitial emphysema were further analysed. A scoring system was devised whereby each of the three zones (upper, middle, and lower) of each lung was subjectively assessed and given a score 0 to 9 , taking into account both the severity (graded 1 to 3 ) and the distribution of the pulmonary interstitial emphysema (graded 1 


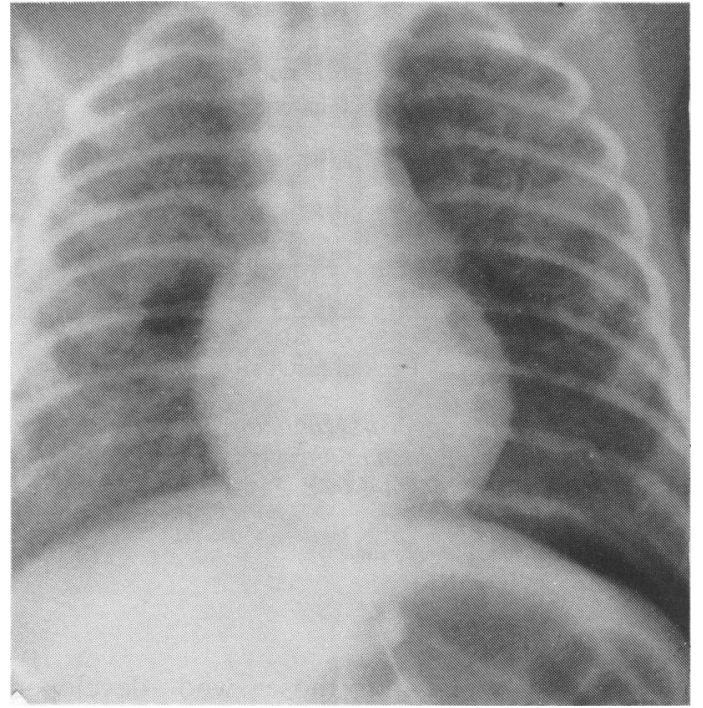

Fig. 1 Chest radiograph showing pulmonary interstitial emphysema in an infant of 28 weeks' gestation.

This was the first radiograph to show pulmonary interstitial emphysema. Severe (grade 3 ) centrally placed (grade 1 ) interstitial air scored 3 points in each midzone, making a total of 6 points for both lungs. There is also a left basal pneumothorax.

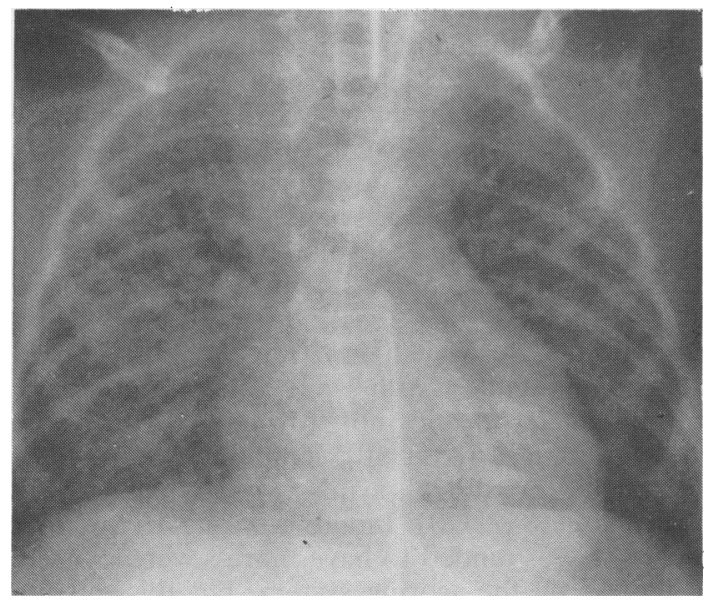

Fig. 2 Chest radiograph showing pulmonary interstitial emphysema in an infant of 25 weeks' gestation.

This infant developed minimal signs on the first postnatal day: the most noticeable changes were present on day 3 and are shown in the figure. This radiograph scored a total of 13 points- the right lung $10(4,4,2)$ and the left 3 $(1,1,1)$.

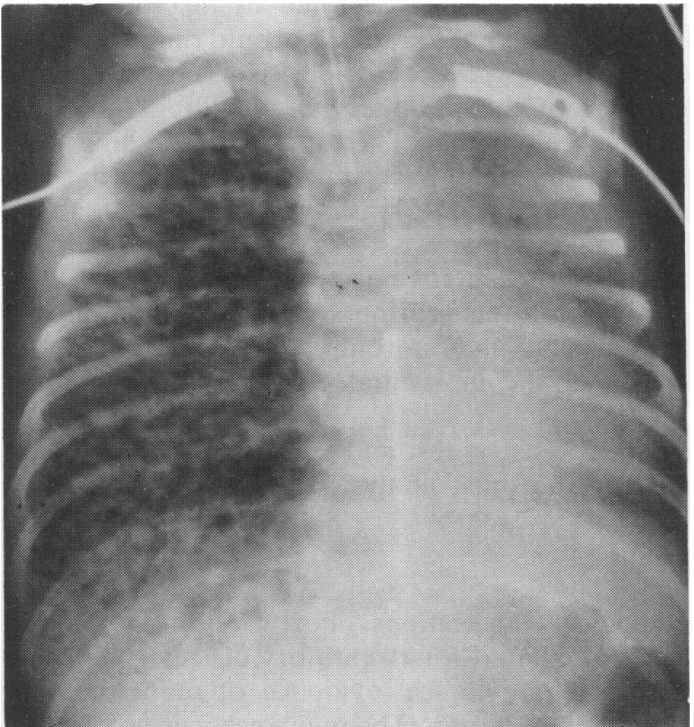

Fig. 3 Chest radiograph showing pulmonary interstitial emphysema in an infant of 29 weeks' gestation.

The most noticeable changes were seen on day 4 . This radiograph scored 24 . with pulmonary interstitial emphysema only really present in the right lung ( 9 $9,9)$. On no radiograph was the endotracheal tube seen to lie in the right main bronchus.

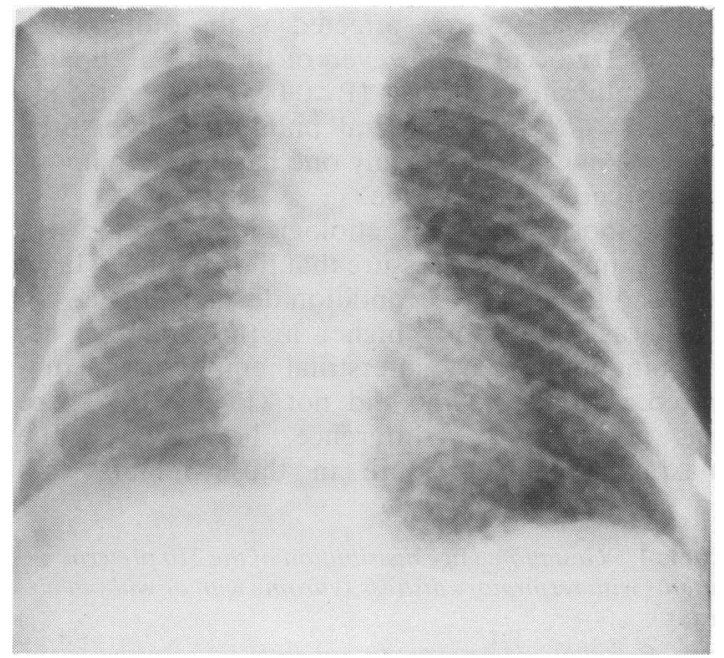

Fig. 4 Chest radiograph showing pulmonary interstitial emphysema in an infant of 31 weeks' gestation.

The highest scoring radiograph (45) was seen on day 3 . At this stage the right lung scored $18(6,9,3)$ while the left scored $27(9,9,9)$ 
to 3). These latter factors were multiplied together so that mild disease, confined to just the medial portion of the zone (grade 1), would only score one point, whereas severe (grade 3) disease extending right out to the periphery of the lung (grade 3) would score 9 points. The totals for each lung were recorded (maximum 27 points) and any asymmetry between the two lungs was noted. The total for each chest radiograph was calculated (maximum 54 points). Representative examples are shown in Figs. 1 to 4 . Using this scoring system we determined if the mortality and morbidity were related to the severity of the interstitial emphysema.

Statistical tests. $\chi^{2}$ test and the Student's $t$ test were used for statistical analysis.

\section{Results}

Aetiological associations. Forty one of the 210 infants ventilated for respiratory distress syndrome developed radiological evidence of pulmonary interstitial emphysema. The incidence was not related to gestational age (Table 1) or birthweight, and although it was more common in babies resuscitated at birth by positive pressure ventilation through an endotracheal tube, this did not reach statistical significance. Nor was there a significant increase among babies ventilated from birth.

Fourteen infants developed asymmetrical pulmonary interstitial emphysema, one lung being at least twice as severely affected as the other. Such asymmetry occurred in seven of the only 10 infants with malpositioned tubes $(\mathrm{P}<0 \cdot 05)$. Among the six infants with true unilateral pulmonary interstitial emphysema, however, only one had had a malpositioned endotracheal tube.

The most significant aetiological association was the maximum peak pressure that the infant had been exposed to before the condition developed (Fig. 5). This was significantly higher in those infants developing pulmonary interstitial emphysema compared with those who did not $(\mathrm{P}<0 \cdot 001)$. There was no significant difference, however, in the maximum peak pressure in those infants who

Table 1 Gestational age distribution of the 210 preterm infants with respiratory distress sydrome with or without air leaks

\begin{tabular}{llll}
\hline $\begin{array}{l}\text { Gestational age } \\
\text { (weeks) }\end{array}$ & $\begin{array}{l}\text { Pulmonary interstitial } \\
\text { emphysema } \\
\text { No (\%) }\end{array}$ & $\begin{array}{l}\text { Pneumothorax only } \\
(\text { No) }\end{array}$ & $\begin{array}{l}\text { No air leak } \\
(\text { No) }\end{array}$ \\
\hline$<27(n=33)$ & $6(18)$ & 6 & 21 \\
$27-29(n=94)$ & $23(24)$ & 22 & 49 \\
$>29(n=83)$ & $12(14)$ & 13 & 58 \\
\hline
\end{tabular}

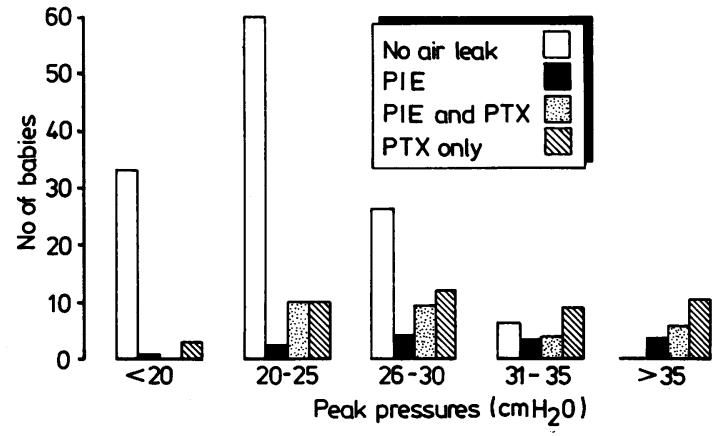

Fig. 5 Relation between peak ventilation pressures and the development of an air leak in infants ventilated for respiratory distress syndrome.

PIE=pulmonary interstitial emphysema. PTX=pneumothorax

developed disease and those who developed pneumothoraces without preceding pulmonary interstitial emphysema.

Morbidity and mortality. There was a significant increase in the incidence of pneumothoraces among babies with pulmonary interstitial emphysema compared to those without it -31 of $41 v 41$ of 169 $(\mathrm{P}<0.001)$. The development of a pneumothorax, however, was not correlated with the severity of the pre-existing condition, as assessed by the scoring system. The maximum peak pressure that the infant was exposed to before the development of pulmonary interstitial emphysema was the same in those infants who did not develop further air leaks as in those who subsequently developed a pneumothorax. Twenty one of the 41 babies with pulmonary interstitial emphysema developed an intraventricular haemorrhage compared with an incidence of 39 of 169 among the remainder $(P<0 \cdot 001)$. Intraventricular haemorrhages were also more common in infants with pulmonary interstitial emphysema who did not subsequently develop pneumothoraces (4 of 10) compared with infants with respiratory distress syndrome who had no form of air leak (18 of 128). Infants with intraventricular haemorrhages tended to have more severe disease, as judged by the scoring system, but this did not reach statistical significance.

The development of pulmonary interstitial emphysema increased the number of babies requiring ventilation for longer than 168 hours or supplementary oxygen for more than 240 hours compared with the remainder $(\mathrm{P}<0 \cdot 05)$, (Table 2$)$, and was especially significant if the 41 infants with 
Table 2 Incidence of prolonged respiratory support in preterm infants with respiratory distress syndrome with or without air leaks

\begin{tabular}{|c|c|c|c|c|}
\hline & \multicolumn{2}{|c|}{ Duration of oxygen therapy (hours) } & \multicolumn{2}{|c|}{$\begin{array}{l}\text { Duration of intermittent positive pressure } \\
\text { ventilation (hours) }\end{array}$} \\
\hline & $<240$ & $>240$ & $<168$ & $>168$ \\
\hline Pulmonary interstitial emphysema (total) & 21 & 20 & 28 & 13 \\
\hline Without pulmonary interstitial emphysema & 118 & 51 & 141 & 28 \\
\hline Pulmonary interstitial emphysema without pneumothorax & 3 & 7 & 8 & 2 \\
\hline Respiratory distress syndfome alone & 106 & 22 & 119 & 9 \\
\hline
\end{tabular}

Table 3 Incidence of need for prolonged respiratory support in preterm infants with pulmonary interstitial emphysema with or without pneumothorax

\begin{tabular}{|c|c|c|c|c|}
\hline & \multicolumn{2}{|c|}{ Duration of oxygen therapy (hours) } & \multicolumn{2}{|c|}{$\begin{array}{l}\text { Duration of intermittent positive pressure } \\
\text { ventilation (hours) }\end{array}$} \\
\hline & $<240$ & $>240$ & $<168$ & $>168$ \\
\hline Pulmonary interstitial emphysema only & 3 & 7 & 6 & 4 \\
\hline Pulmonary interstitial emphysema and pneumothorax & 17 & 14 & 22 & 9 \\
\hline
\end{tabular}

pulmonary interstitial emphysema were compared with babies without any form of air leak, respiratory distress syndrome alone, $(\mathrm{P}<0 \cdot 001)$, (Table 2). Pulmonary interstitial emphysema without a subsequent pneumothorax also significantly increased the number of infants requiring prolonged oxygen therapy $(\mathrm{P}<0.001)$ and artificial ventilation $(\mathrm{P}<0.01)$ (Table 2) compared with the respiratory distress syndrome alone group. Among the infants with pulmonary interstitial emphysema, however, the addition of a further air leak did not alter the need for prolonged respiratory support (Table 3 ). There was, however, no significant difference in the number of infants with and without pulmonary interstitial emphysema developing chronic lung disease (defined as the need for more than three weeks respiratory support).

The mortality of babies with pulmonary interstitial emphysema (10 of 41) was not significantly higher than that of infants without the condition (31 of 169) and there was no statistical difference in the mortality rates between infants with pulmonary interstitial emphysema who subsequently developed pneumothoraces and those who did not (Table 4). Infants with this condition who died tended to have more severe disease, as assessed from their chest radiographs but this did not reach significance.

Treatment. Twelve infants were treated with fast rate ventilation (rates greater than 110 /minute) as soon as pulmonary interstitial emphysema was diagnosed. The infants in both treatment groups, that is receiving slow or fast rate ventilation, were of similar gestational ages and postnatal ages when the condition was first diagnosed (Table 5). Although the infants started on fast rate ventilation tended to have more severe disease this did not reach statistical significance. Nine infants were paralysed as soon as they developed pulmonary interstitial emphysema (five from the fast rate group) and two subsequently developed a pneumothorax. All four babies paralysed on slow frequency ventilation developed further air leaks.

In eight infants the change to fast rate ventilation enabled peak pressures to be lowered within the subsequent two hours (mean $4.9 \mathrm{~cm} \mathrm{H}_{2} \mathrm{O}$, range 2 to $8 \mathrm{~cm} \mathrm{H}_{2} \mathrm{O}$ ), however, in two others peak pressures had to be increased (mean $2.5 \mathrm{~cm} \mathrm{H}_{2} 0$, range 2 to 3 $\mathrm{cm} \mathrm{H}_{2} \mathrm{O}$ ).

Only two infants treated with fast rate ventilation subsequently developed a pneumothorax, one of whom had required increased pressures on changing to the faster rates. Twenty nine babies remained on conventional ventilator rates (rate 30 to 40 ) and 25 developed pneumothoraces $(P<0 \cdot 001)$.

Although fast rate ventilation reduced the incidence of penumothoraces, the pulmonary interstitial emphysema in those infants deteriorated significantly $(\mathrm{P}<0.05) \quad($ Table 5). There was less

Table 4 Mortality among 210 preterm infants with respiratory distress syndrome with or without air leaks

\begin{tabular}{lr}
\hline Respiratory distress syndrome alone & 15 of 128 \\
$\begin{array}{l}\text { Pneumothorax alone } \\
\text { Pulmonary interstitial emphysema only }\end{array}$ & $\left.\begin{array}{r}16 \text { of } \\
41\end{array}\right\} 31$ of 169 \\
$\begin{array}{l}\text { Pulmonary interstitial emphysema plus } \\
\text { pneumothorax }\end{array}$ & 8 of 31$\} 10$ of 41 \\
\hline
\end{tabular}


Table 5 Clinical characteristics of two groups of preterm infants with respiratory distress syndrome and pulmonary interstitial emphysema treated with fast rate or slow rate ventilation. (Values mean $(S D)$ )

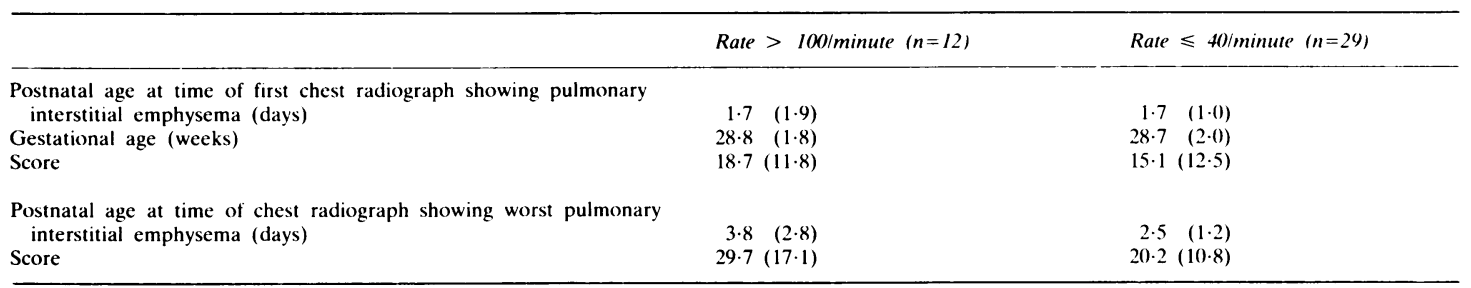

progression of the disease in babies remaining on slow rate ventilation, however most had developed pneumothoraces.

Despite a reduction in the number of pneumothoraces in the fast rate group, there was no other improvement in outcome; in particular no significant alteration in the mortality, incidence of intraventricular haemorrhage, or requirement for prolonged respiratory support.

\section{Discussion}

Pulmonary interstitial emphysema may occasionally occur spontaneously in preterm babies with respiratory distress syndrome, but it is more usually associated with the use of intermittent positive pressure ventilation ${ }^{8}$ and may be another consequence of iatrogenic barotrauma. In this study the most significant association with the development of this condition was the use of high peak pressures, as has been found with pneumothoraces. ${ }^{9}$ The increased severity of disease found after incorrect positioning of the endotracheal tube down one main bronchus, seen in this study and others, ${ }^{8}$ is further evidence for an aetiological role of barotrauma in this condition. Very preterm infants exposed to such high inflating pressures are more likely to develop pulmonary interstitial emphysema, as the increased amount of pulmonary connective tissue in the immature lung ${ }^{10}$ is more likely to trap air which has ruptured an alveolus.

The mortality in this study $(24 \%)$ compares favourably with the $67 \%^{11}$ and $39 \%^{12}$ reported previously. We were unable to confirm that the presence of pulmonary interstitial emphysema significantly increased the mortality nor, as reported by Gregoire, ${ }^{12}$ that where it developed on the first postnatal day it was always bilateral and usually fatal.

We were able to show that fast rate ventilation significantly reduced the number of penumothoraces among these infants. The use of lower peak pressures used in most infants at fast rate ventilation may in part explain this reduced incidence. In other respects the final outcome of these infants was not altered, there being no difference in the mortality, incidence of intraventricular haemorrhage, or chronic lung disease between the fast or slow rate group; however, the mortality in our series was already low. ${ }^{11} 12$ The failure to reduce the incidence of intraventricular haemorrhage and chronic lung disease in the group undergoing fast rate ventilation suggests that pulmonary interstitial emphysema alone is an important cause of morbidity and its prevention is therefore as important as preventing further air leaks.

It is interesting to speculate why the pulmonary interstitial emphysema actually worsened during fast ventilation. In the absence of a pneumothorax, and particularly a pneumomediastinum, the pulmonary interstitial emphysema would be unable to decompress. ${ }^{8}$ At the faster ventilator rates insufficient expiratory time could have caused further accumulation of trapped air. Inadvertent positive end expiratory pressure can be a consequence of fast rates and could have compounded this problem, but it was not encountered in this study.

We have been able to show that the use of high peak pressure ventilation is important in the causation of pulmonary interstitial emphysema and that fast rate ventilation may prevent pneumothoraces from occurring subsequently. In this study, however, fast rate ventilation was only used after the infants had already been exposed to high pressure ventilation, which may explain the relative lack of success of this form of treatment in reducing serious morbidity and mortality. We would therefore suggest from these preliminary findings that a controlled study of the use of fast rate ventilation from birth before the pulmonary interstitial emphysema has developed is necessary.

We thank Dr J Tudor, who reported many of the original chest radiographs and gave helpful advice and Dr G Gandy and Dr C J Morley, who with NRCR, were in clinical charge of the patients in this study, for help and encouragement. 


\section{References}

I Plenat F, Vert P. Didier F, Andre M. Pulmonary interstitial emphysema. Clin Perinatol 1978;5:351-75.

2 Dagbjartsson A, Brallier D, Avery GB. Pulmonary air leak in infants with hyaline membrane disease. Clinical Proceedings 1977;33:169-74.

3 Ogata ES, Gregory GA, Kitterman JA, Phibbs H, Tooley WH. Pncumothoraces in RDS: incidence and effect on vital signs; blood gases and pH. Pediatrics 1976;58:177-83.

+ Hill A. Pelman JM. Volpe JJ. Relationship of pneumothorax to occurrence of IVH in the premature newborn. Pediatrics 1982:69:144-9

5 Frantz ID. Stark AR, Westhammer J. Improvement in pulmonary interstital emphysema with high frequency ventilation. Pediatr Res 1981:15:719.

${ }^{6} \mathrm{Ng} \mathrm{KPK}$, Easa D. Management of interstitial emphysema by high frequency low positive pressure ventilation in the neonate. $J$ Pediatr 1979;95:117-8.

7 Campbell R. Interpulmonary interstitial emphysema: a complication of hyaline membrane disease. Am J Roentgenol 1970;110:449-56. $\checkmark$ Thibcault DW. Pulmonary barotrauma: interstitial emphysema, pneumomediastinum and pneumothorax. In: Thibeault DW, Gregory GA, eds. Neonatal pulmonary care. London: Addison Wesley, 1978:307-17.

9 Oh W, Stern L. Discases of the respiratory system. In: Behrman RE, ed. Neonatal and perinatal medicine: diseases of the foetus and infant. St Louis: CV Mosby, 1977: 558.

10 Reid L, Rubino L. The connective tissue septa in the foetal human lung. Thorax 1958;14:35.

1 Hart SM, McNair M, Gamsu HR, Price JF. Pulmonary interstitial emphysema in very low birthweight infants. Arch Dis Child 1983;58:612-5.

12 Gregoire R, Yulish B, Martin R, Fletcher B, Fanaroff A. Natural history of pulmonary interstitial emphysema in the preterm infant. Pediatr Res 1979;13:1019.

Correspondence. to Dr Anne Greenough, University Department of Paediatrics, New Addenbrooke's Hospital, Cambridge.

Received 14 June 1984

\section{Fifty years ago}

\section{Sunlight and pink disease}

\section{J v C Braithwaite (Leicester) - Arch Dis Child 1934;9:198}

'That sunlight has a causal relation to pink disease is indicated by its prevalence in sunny countries, its seasonal incidence in England, its predilection for the country and suburbs, and the bad effects of exposing patients to the sun (one patient died a few hours after unintentional exposure, and another showed signs of collapse). The condition is greatly ameliorated and the course of the disease is shortened by keeping the children away from sunlight. Blood diluted with saline and exposed to sunlight was haemolysed except when it was taken from anaemic patients. This occurred through glass as well as quartz. Ultraviolet light produced no haemolysis through glass, neither did white light from a 2 kilowatt lamp. Exposing the blood saline mixture to heat, however, produced haemolysis. At $52^{\circ} \mathrm{C}$ blood was haemolysed less rapidly when obtained from a patient with pink disease than when it came from other children, but at $55^{\circ} \mathrm{C}$ haemolysis occurred more rapidly. Blood from children with pneumonia behaved in a similar way. It was therefore concluded that the noxious influence of the sun was due largely to heat, and this was confirmed by treating the condition by cold sponging, light clothing, etc. Two patients so treated were apparently well in a fortnight.

(Better still to avoid mercury-containing teething powders - RONALD ILLINGWORTH). 